\title{
RESENHA
}

\section{LETRAMENTO CRÍTICO NA SOCIEDADE DIGITAL}

\author{
Cleisiane de Sousa Silva
}

TAKAKI, N. H. Letramentos na Sociedade Digital: navegar é e não é preciso. Jundiaí: Paco Editorial, 2012.

"Letramentos na sociedade digital: navegar é e não é preciso" é uma obra que traz o estudo sobre as novas formas de navegação dos jovens na internet. Baseia-se em concepções recentes sobre letramentos e multiletramentos, principalmente letramentos críticos, como práticas sociais. A autora é Nara Hiroko Takaki, possui 3 capítulos e compõe-se de 228 páginas. Essa obra faz parte da Paco Editorial e sua primeira edição foi no ano de 2012, em Jundiaí - SP. Este livro é uma versão um pouco modificada da tese de doutorado de Nara, traz novas epistemologias em meio à construção complexa de conhecimento em rede. A pesquisadora analisou os posicionamentos de uma comunidade de discentes universitários, de como interpretam materiais virtualmente produzidos ou veiculados, pela observação de mensagens enviadas por eles utilizando 0 site http//:www.webnarah.pro.br/old, site criado para uma investigação de como os hiperleitores constroem saberes a partir de suas interações com os textos virtuais.

Na introdução, Takaki (2012) apresenta a questão da sociedade globalizada e o ágil crescimento dos meios de comunicação em rede e dos novos modelos de linguagem. Há formas diferentes e simultâneas de interação humana e mudança nas exigências pelas transformações de

\footnotetext{
1 Mestranda do programa de Pós-Graduação "Processos Socioeducativos e Práticas Escolares", do Departamento de Ciências da Educação, da Universidade Federal de São João Del-Rei (UFSJ), Minas Gerais, Brasil. E-mail: cleise.sousa@gmail.com
} 
ordem sócio-histórica, política-econômica e cultural. Portanto, entender a diversidade das interpretações, suas razões históricas e suas implicações na constituição de cidadãos críticos, inventivos, éticos e conectados se faz necessário. A partir do letramento, é possível compreender variados discursos, e a leitura, nesse ponto de vista, permite minimizar as desigualdades de natureza social. O posicionamento crítico de tais leitores pode ser proporcionado pela internet, com base em reflexões diversas, e o espaço cibernético é um local no qual os usuários podem criar um meio de interesses similares, como exemplo as redes sociais. Sugere-se, então, uma reeducação para o enfrentamento crítico dessas novas mídias.

No primeiro capítulo, intitulado "Os "novos" letramentos e o hiperleitor", Takaki (2012) aponta um rápido histórico sobre os letramentos e suas transformações, relatando que a socialização com o texto acontece pela criticidade. A autora se fundamenta na perspectiva de alguns autores sobre o tema, para fazer uma abordagem sobre o "letramento crítico" e também sobre as influências na sua formação, evidenciando que uma delas ocorreu da teoria crítica social, "como: alívio do sofrimento dos oprimidos, crítica aos problemas sociopolíticos e alternativas para uma sociedade mais justa" (p. 40).

Segundo Takaki (2012), os letramentos transformaram-se em uma indústria e a autora expressa que as dimensões operacional, cultural e crítica se mostram interligadas e que em todas as etapas está presente o elemento da criticidade. O hiperleitor terá espaço de papel ativo que modificará os significados de forma crítica, conforme o seu conhecimento de mundo, cultural, habilidades técnicas e prática social. A autora indica a importância para a sociedade de estudos que enfocam uma educação direcionada para uma das formas de letramentos, o letramento digital, e justifica o tema da obra como forma de colaboração para a área da educação.

No subitem 1.1 "Sobre os "novos" letramentos", Takaki (2012) embasa o tema, citando que é relevante ter novas maneiras de pensar para analisar o obsoleto e compreender os novos letramentos, para fazer uma 
preparação e expansão do pensamento e refletir sobre o futuro. Em seguida, expõe que o que vem sucedendo fora da esfera escolar e evidencia que muitas escolas precisam de uma melhor "aceitação dos desafios dos novos letramentos e que as novas tecnologias estão demandando, cada vez mais, outras práticas culturais para o futuro do aprendiz, cuja rotina já é influenciada pelos efeitos tecnológicos" (p. 52). As práticas pedagógicas estão desatualizadas e não estão conseguindo acompanhar a agilidade das mudanças nos meios de comunicação, surgindo, assim, uma tensão. A interação por meio de tecnologias digitais faz com que essas pessoas sejam produtivas no meio digital, uma construção de conhecimento em rede. Há, ao final desse subitem, a assertiva de que o hipertexto está ligado a outros hipertextos por intermédio de um sistema intertextual como um livro, e a diferença é a ampla valorização de impacto de informações.

No subitem 1.2 "A hermenêutica crítica e suas relações com o letramento crítico", a autora fala sobre reinterpretar textos por meio da renovação de olhares, "o intérprete fenomenológico é interpelado por um silenciamento e recolhimento dos sentidos, os quais não o encorajam a participar ativamente de uma reconstrução de significados" (p. 62). Para Takaki (2012), "tal hermenêutica desconstrói sentidos já congelados historicamente e abre-se para um mundo do texto e para novas maneiras de ser" (p. 66). Então, perguntar o que o texto aparentemente diz transforma-se num processo através do qual construímos novos significados e que a habilidade interpretativa do público que torna o texto significativo.

No subitem 1.3 "A questão da crítica nas teorias de letramentos", Takaki (2012) faz uma observação dos comentários dos hiperleitores sobre a invasão autoritária da cultura da mídia e das leis de mercado. E expõe que os conflitos da sociedade digital é gerado possivelmente pelos resultados desse mundo que se orienta por artefatos digitalizados, influenciando as avaliações de hiperleitura. Fala sobre a capacidade de absorver formas culturais variadas numa rede de comunicação multimodal e maleável pela nova galáxia digital, relatando também que a leitura é uma filosofia de si 
mesmo, reflexão sobre como ontologias pessoais se relacionam com epistemologias que the são alheias na prática teórica. O espaço digital proporciona oportunidades para epistemologias emergentes que trazem contribuição para a "expansão das pesquisas convencionais, ensino e aprendizagem informais, maior autoria com novas epistemologias de conhecimento e performatividade" (p. 80).

No segundo capítulo, intitulado "A interpretação na linguagem digital: a construção de sentidos dos hiperleitores", a autora investiga algumas mensagens e percepções dos universitários pesquisados sobre o uso da internet em seu site "webnarah", e descreve algumas observações a partir de debates desses alunos em relação ao tema do compartilhamento de informações em rede. Takaki (2012) faz referência ao fato de que nem todos utilizam o computador, então não é uma consequência da rapidez e expansão para troca de informações e posteriormente, no texto, expressa que não saber usar o computador não significa que o usuário não tenha senso de criticidade em sua interpretação, dizendo que produções criativas podem ocorrer pelo compartilhamento de conhecimento. Mas, ao mesmo tempo, e contraditoriamente, a falta de controle sobre as próprias descobertas pode fazer surgir sentimentos de medo, ansiedade, desconforto e insegurança. "Novas formas de divisão de poder entre o homem e a máquina" (p. 91). A autora Atenta para o fato da instrução do hiperleitor para uma ampliação da habilidade crítico-interpretativa, criativa e ética contribuirá para que esta influência não esteja ameaçada.

De acordo com Takaki (2012), no ambiente escolar, há uma certa resistência em relação ao tema, por se acharem sem conhecimento suficiente nesse contexto. As escolas em áreas menos privilegiadas poderão ficar de fora, sinalizando que as novas tecnologias representam soluções para muitos problemas, e ao mesmo tempo, inauguram outros conflitos na sociedade. Entretanto, os problemas sociais, aparentemente, são mais complexos e difíceis de lidar, envolvem mudanças de comportamento e atitude. A autora ainda destaca a importância de o hiperleitor saber 
articular, posicionar-se criticamente e construtivamente em sua leitura de mundo, em uma conscientização de que as "linguagens escrita e falada não dão conta de explicar as narrativas maleáveis on-line; atentar-se para o fato de que navegar é e não é preciso" (p. 137-138). A sociedade pratica letramentos críticos, quando muitos hiperleitores fazem uma reflexão e têm discernimento sobre os conteúdos, confiam e desconfiam do mesmo.

No terceiro capítulo, intitulado "O letramento crítico e a linguagem visual na interação dos hiperleitores", Takaki (2012) indica que as experiências no mundo mostra que organizamos nossos prazeres, medos e necessidades, com base naquilo que vemos e observamos. O poder da experiência da visualização faz com que cada intérprete da imagem sinta e se emocione de forma diferente e única. A autora coloca também que "o evento é processado por uma experiência pessoal, emocional, cultural e, por esse motivo, tal mapeamento mental é indiscutivelmente sociocultural" (p. 148). Narrativas socialmente compartilhadas são contemporizadas pelo trabalho da memória e mente, há uma interação com a imagem do objeto. Há um reforço autoral em afirmar que navegar é e não é preciso, pois o meio digital possibilita a construção de conhecimento em meio a coexistência de recursos numa velocidade, outrora impossível.

Takaki (2012) conclui a obra, considerando que o letramento crítico digital no espaço educacional vem sinalizar que os hiperleitores têm a capacidade de perceber que houve uma mudança na rotina provocada pelo saturamento social; as rápidas mudanças nos meios de comunicação demandam um desenvolvimento de habilidades e de conhecimento constantes.

Em síntese, o texto destaca a importância da criticidade em relação ao uso das novas tecnologias, explanando que o letramento digital é uma temática essencial à aprendizagem e sociedade. Uma educação interativa e proativa no mundo, orientada para uma cidadania comprometida.

Os letramentos na sociedade digital constituem um assunto ainda com muitos desafios diante de suas dificuldades e polêmicas. A sociedade em 
DOI: $10.24065 / 2237-9460.2019 v 9 n 2 I D 867$

rede atual e a exposição de pensamentos na internet com liberdade nesse espaço expressam uma nova forma de ler e escrever, mas o acesso à tecnologia ainda não abrange as pessoas como um todo, e a escola é um meio para que haja a democratização desses recursos tecnológicos. O indivíduo considerado letrado nessa área é o que tem aprendizagem digital e desenvolve uma consciência crítica das informações midiáticas.

Logo, surge a problemática de como construir essa noção da crítica em relação a esses letramentos. Levar essa conscientização das pessoas para o âmbito escolar é muito importante e já é um passo, o educador terá uma nova oportunidade de reformular seus métodos de ensino e aperfeiçoar sua didática, permitindo uma inclusão digital, a formação de cidadãos críticos na sociedade em rede e letramentos digitais. Essa é uma obra aconselhada para educadores que desejam aperfeiçoar seu conhecimento sobre esse tema e pesquisadores como ótimo referencial de pesquisa. $O$ método de pesquisa apresentado pela autora foi bem sustentado e apoiado, pois a pesquisa de campo deu-lhe uma ótima argumentação e fundamentação para suas assertivas e conclusões.

Recebida em: 25 de maio de 2018. Aprovada em: 27 de abril de 2018. 